\title{
Effect of Emotion-focused Cognitive Behavioral Therapy on Social Adjustment and Experiential Avoidance in Iranian Disabled Veterans
}

\author{
Atadokht. $A^{1}$ \\ ${ }^{*}$ Gharib Bolouk. M² \\ Mikaeli. N3 \\ Samadifard. $\mathrm{HR}^{4}$ \\ 1- Ph.D. in Psychology, \\ Associate Professor, Faculty \\ of Educational Sciences, \\ University of Mohaghegh \\ Ardabili, Iran. \\ 2- ( ${ }^{*}$ Corresponding Author) \\ Ph.D. Student of Psychology, \\ Faculty of Educational \\ Sciences and Psychology, \\ University of Mohaghegh \\ Ardabili, Iran. \\ Email: masoumeh \\ gharibbolouk@uma.ac.ir \\ 3- Professor of Psychology, \\ Faculty of Educational \\ Sciences, University of \\ Mohaghegh Ardabili, Iran. \\ 4- Ph.D. Student of Psychology, \\ Faculty of Educational \\ Sciences and Psychology, \\ University of Mohaghegh \\ Ardabili, Iran.
}

\begin{abstract}
Introduction: Lack of social adjustment and experiential avoidance is attributed to many disorders and behavioral problems. The current study aimed at determining the effect of emotion-focused cognitive behavioral therapy (ECBT) on social adjustment and experiential avoidance in Iranian disabled veterans.
\end{abstract}

Materials and Methods: The current semi-experimental study with the case and control groups and pretest and posttest design was conducted on 40 Iranian disabled veterans covered by Bonyad Shahid of Gilan-e-gharb City in 2018. The subjects were selected by convenience sampling method. The demographic information, the Paykel social adjustment, and the Bond acceptance and action questionnaires were employed for data collection. Data were analyzed using MNCOVA.

Results: The obtained results showed a significant decrease in the mean score of experiential avoidance in the training group after receiving ECBT compared with the control group $(\mathrm{P}<0.05)$. Also, the mean score of social adjustment was significantly lower in the intervention group after receiving the treatment compared with that of the control group $(\mathrm{P}<0.05)$.

Discussion and Conclusion: ECBT was effective with the emphasis on correcting distorted cognition and teaching new behaviors, understanding excitement, understanding emotion, and adjusting excitement to increase social adjustment and reduce experiential avoidance in disabled veterans.

Keywords: Behavioral Therapy, Social Adjustment, Veteran. 


\title{
اثربخشى درمان شناختى -رفتارى هيجان مدار بر ساز كارى اجتماعى و اجتناب تجربى در جانبازان داراى نقص عضو لقان
}

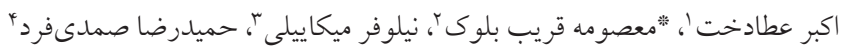

جكيده

مقدمه: ناساز كارى اجتماعى و اجتناب تجربى با بسيارى از اختلالات و مشكلات رفتارى مرتبط است. با توجه به اهميت اين امر يزوهش حاضر با هدف اثربخشى درمان شناختى-رفتارى هيجان مدار بر سازگارى اجتماعى و اجتناب تجربى در جانبازان داراى نقص عضو انجام كرفت.

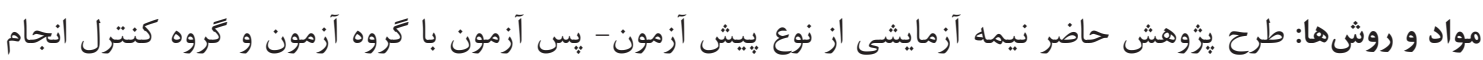

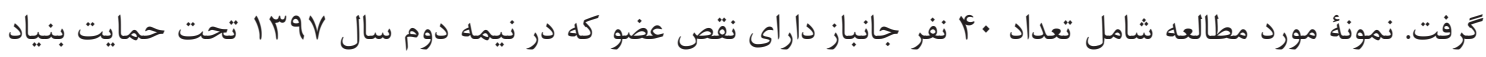

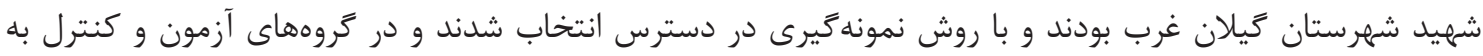

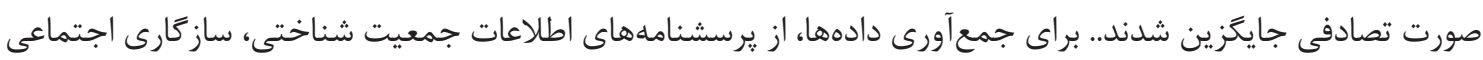

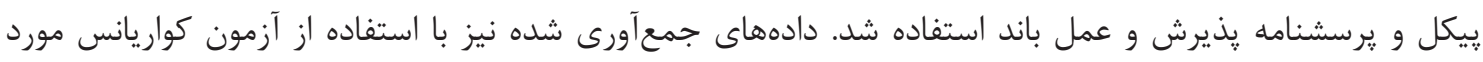

$$
\text { تحليل قرار كرفت. }
$$

يافتها: نتايج تحليل كواريانس نشان داد كه بعد از تعديل نمرات يُش بيش آزمون، ميزان ميانكين نمرات اجتناب تجربى در

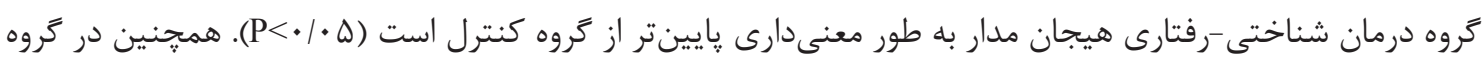

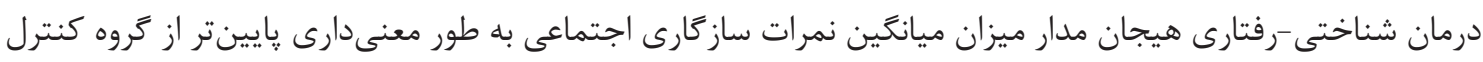

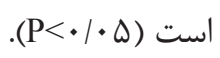

بحث و نتيجه

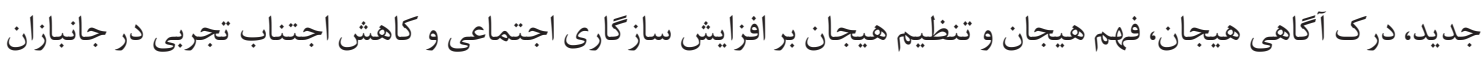
داراى نقص عضو مؤثر است. كلمات كليدى: درمان شناختى-رفتارى هيجان مدار، سازكارى اجتماعى، اجتناب تجربى، نقص عضو.

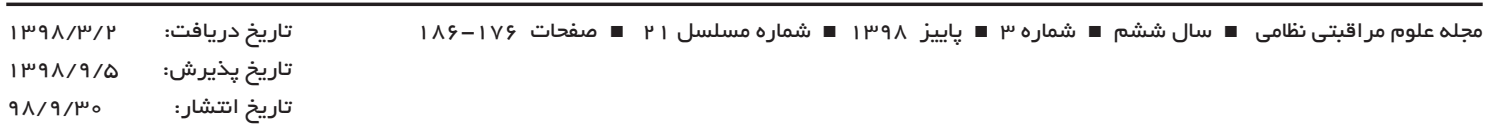

زناشويى و خانوادىى، مشكلات شغلى، انواع اختلالات اضطرابى،

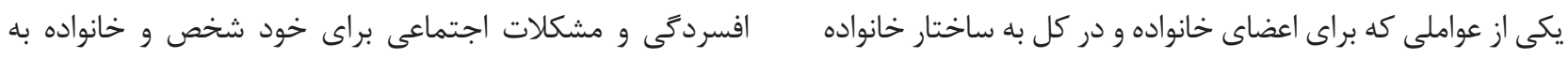

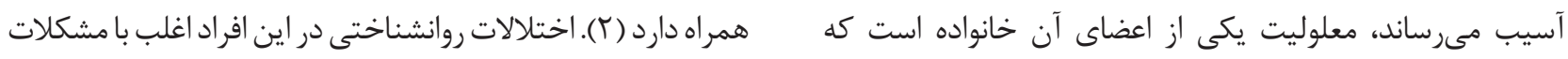

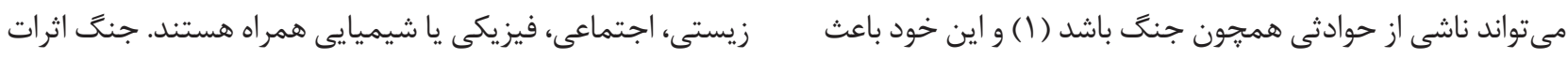

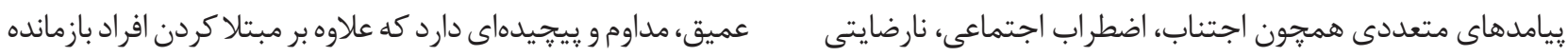


جرا كه اينها باعث مشكلات روانى و يادآور درد و رنج مىشوند،

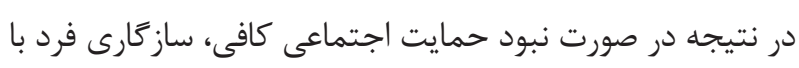

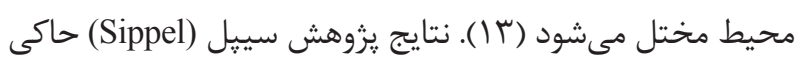

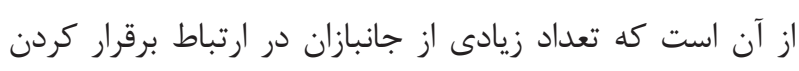

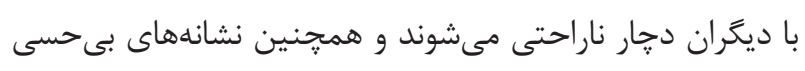

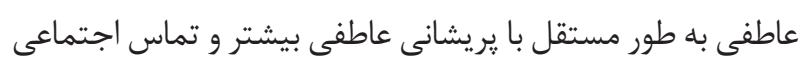

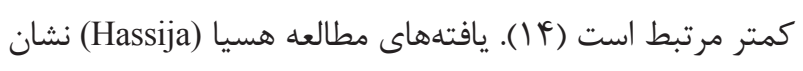

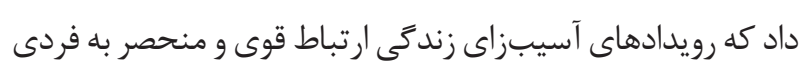
با سازحارى اجتماعى و عملكرد اجتماعى بخصوص، فعاليتهاى

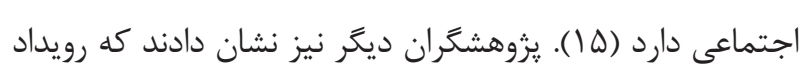

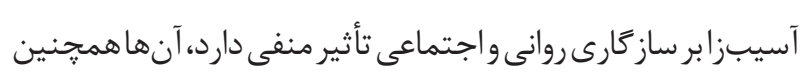

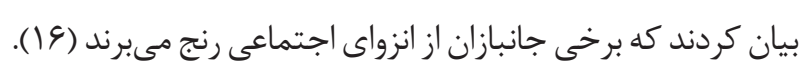

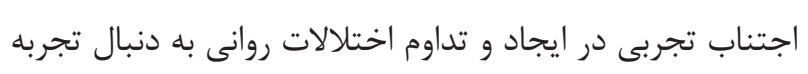
رويدادهاى آسيبزا نقش مهمى دارد، حتى زمانى كه افسردى إنى نداد

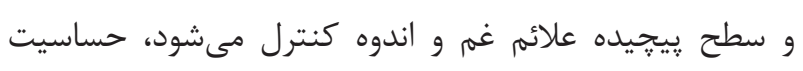

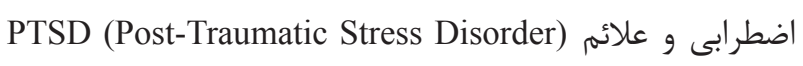
و اضطراب، تنها در ميان افرادى كه اجتنابتجربى بالايى دارند،

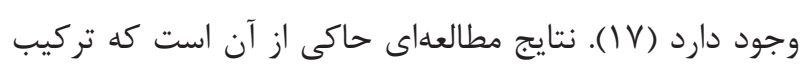
شناختى و اجتناب تجربى كه دو فرايند مرتبط و اصلى نسبت به داريه

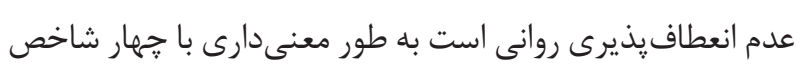

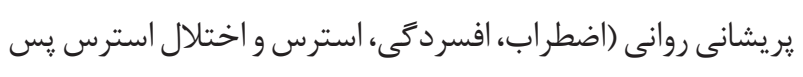
از سانحه) مرتبط است (1 (1). در يك مطالعه نشان داده شد كه ابعاد

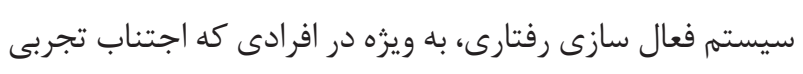

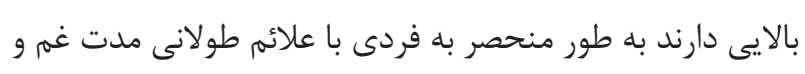

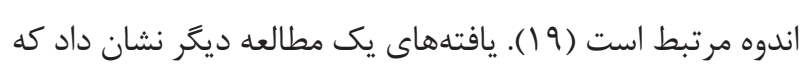

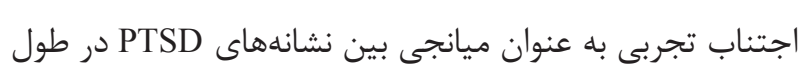

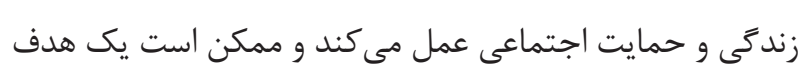

مهرم براى بهبود و درمان علائم PTSD باشد (· (r).

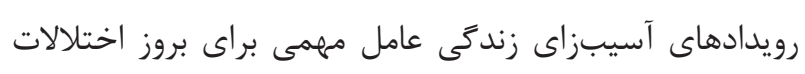

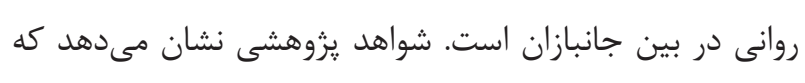

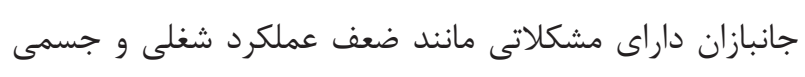

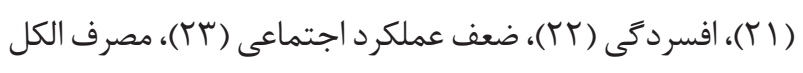

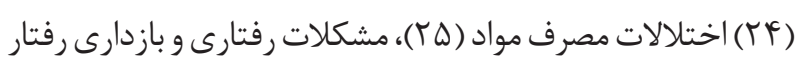

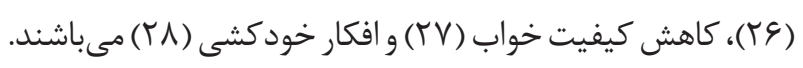

به اختلال استرس يس از سانحه خانواده و مراقبت كنندكان آنها

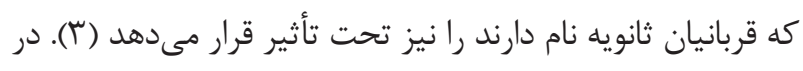

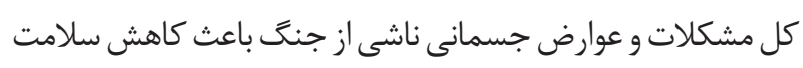

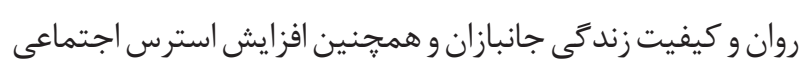
آنان مىشود (1). مطالعات انجام شده مؤيد اين نكته بوده است كه كه

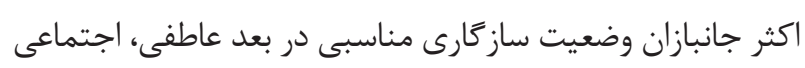
و سلامتى ندارند (ه). ساز گارى اجتماعى (Social Adjustment)،

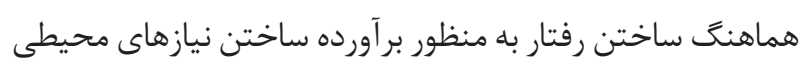

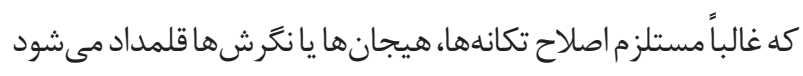
(9). از طرفى يكى از عوامل خطر آفرين بعد از مواجه شدن با آسيب،

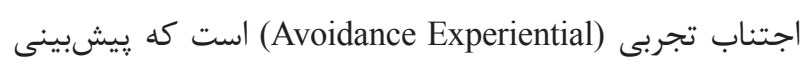

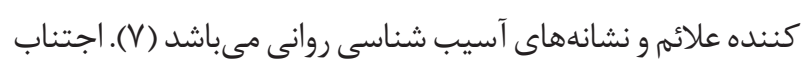

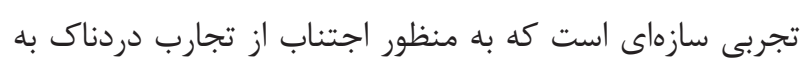

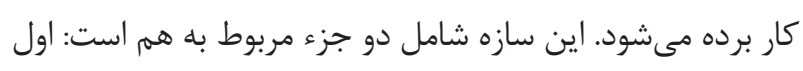

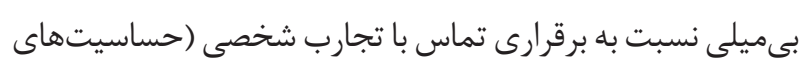

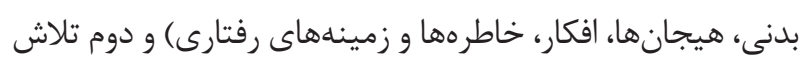

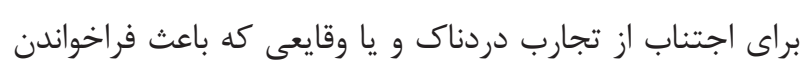

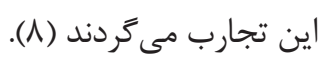

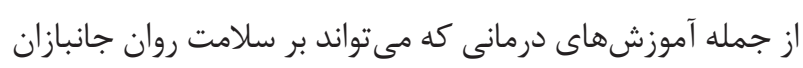

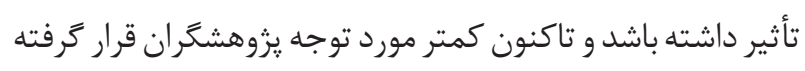
است، درمان شناختى -رفتارى هيجانمدار (Emotion-Focused Cognitive Behavioral Therapy-ECBT) مهارت در شناسايى و تشخيص هيجانات خود و ديخران (آكاهى

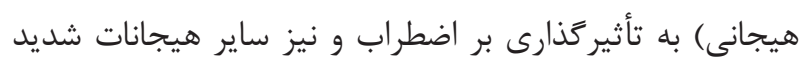

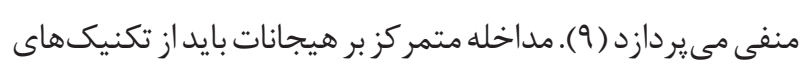
افزايش تجارب هيجانى بر اساس راهبردهاى اجتنابى باشد (• • ().

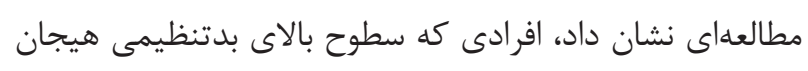

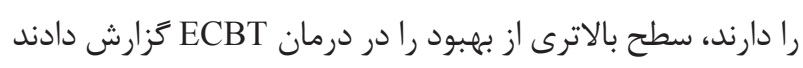

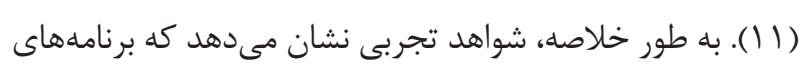
(Cognitive Behavioral Therapy) CBT

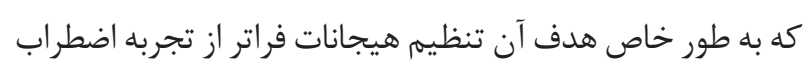

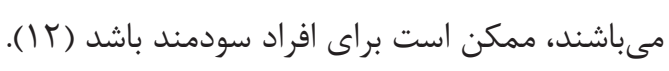

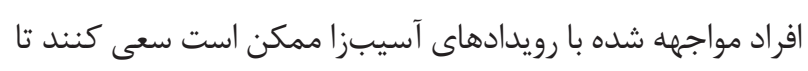
از رويدادهايى كه يادآور لحظات ناراحت كننده هستند اجتناب كند، 
شدن با انفجار مين منجر به نقص عضو، در بعد از دوران جنَ

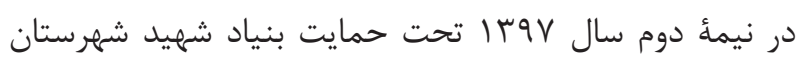

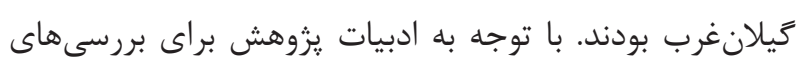

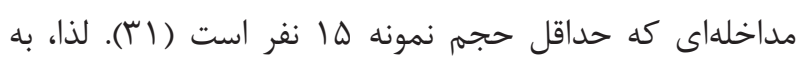

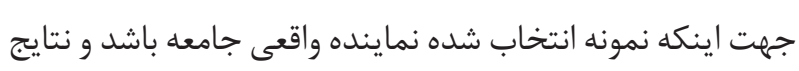

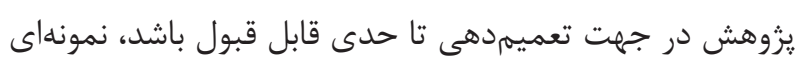

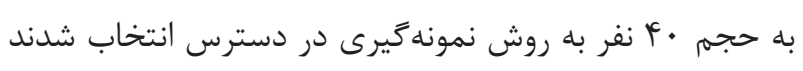

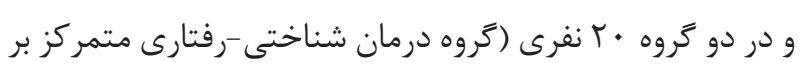

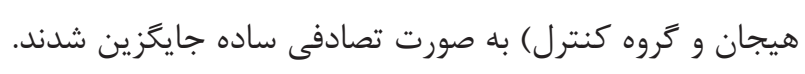

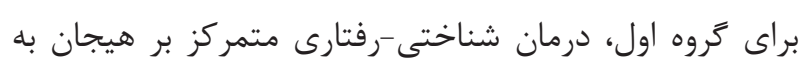

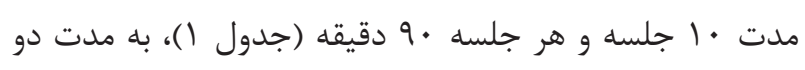

همجنين نبود ساز گارى اجتماعى باعث اختلال در عملكرد شناختى

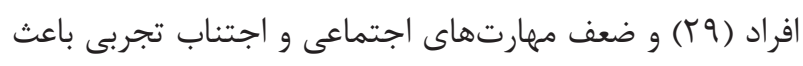

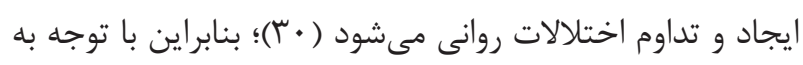
اهميت اين امر، يزوهش حاضر با هدف تعيين اثربخشى درمان إنان

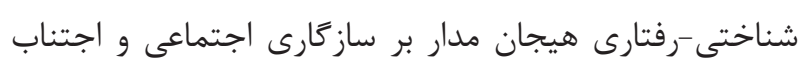

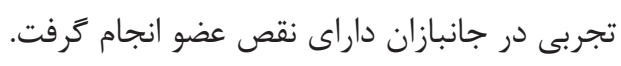

\section{مواد و روشها}

روش يزوهش حاضر نيمه آزمايشى از نوع طرحهاى ييش آزمون - مون

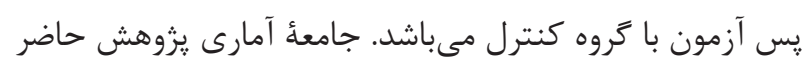

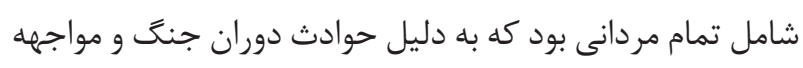

جدول ا- ساختار جلسات درمان شناختى-رفتارى هيجان مدار

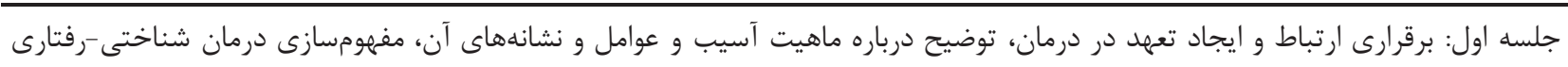

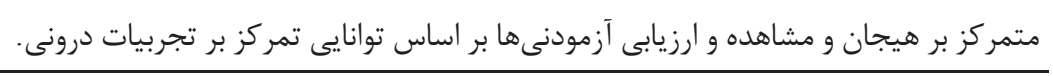

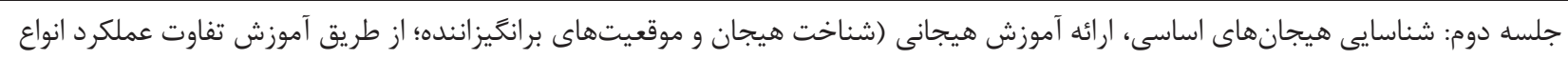

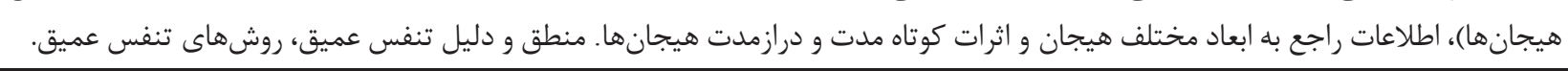

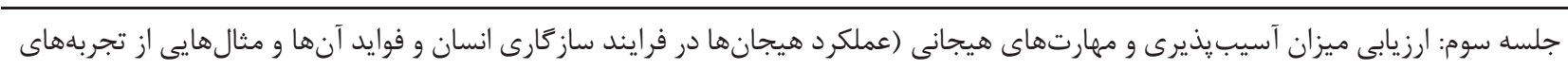

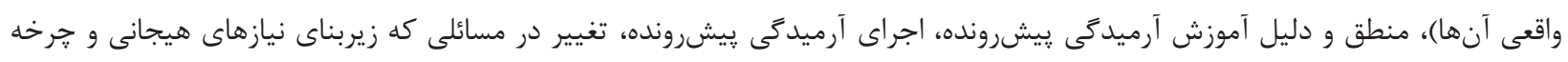

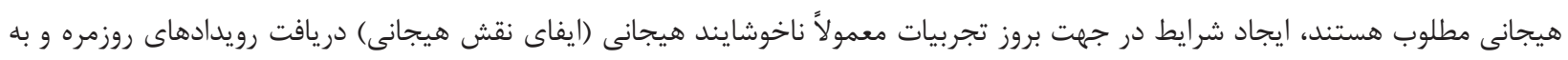
حالش كشيدن آنها.

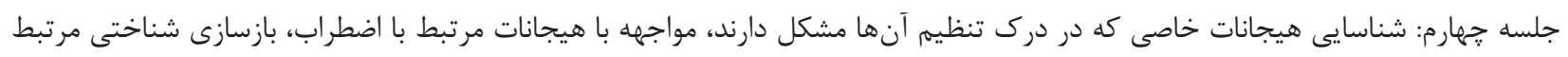

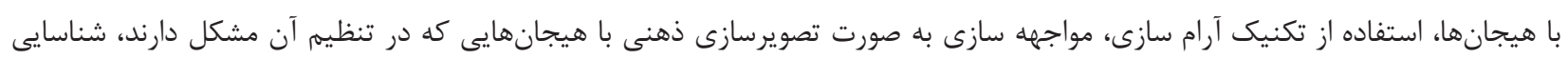

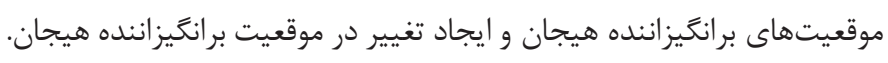

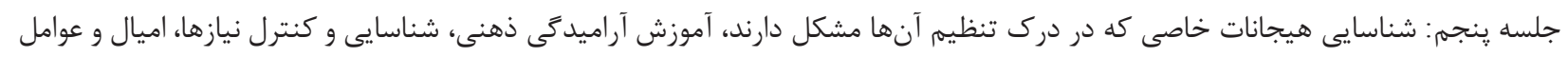

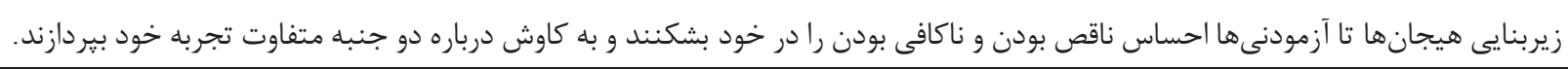

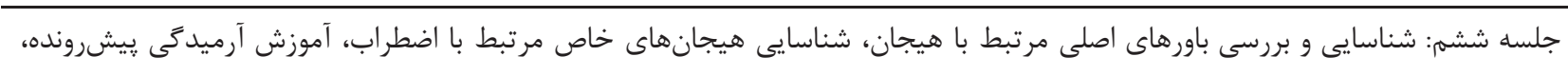

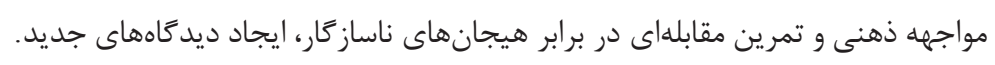

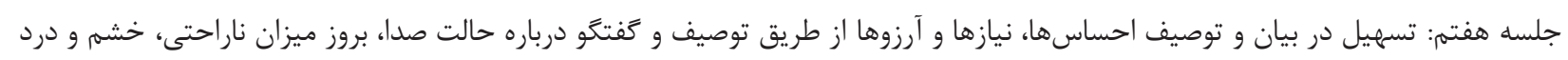

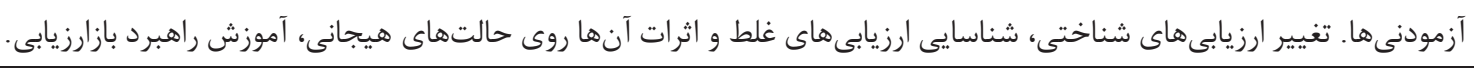

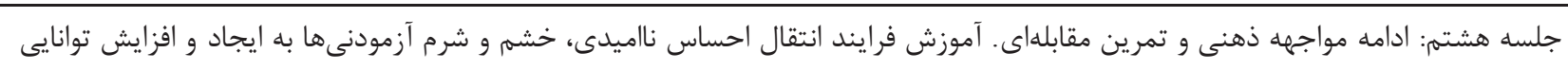

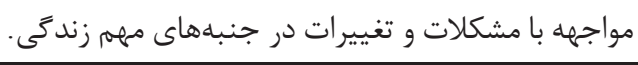

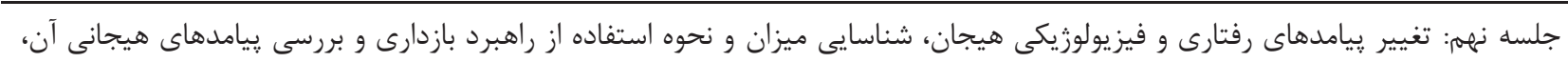

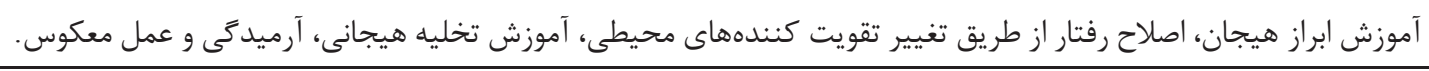

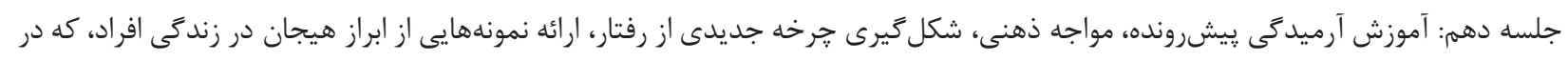

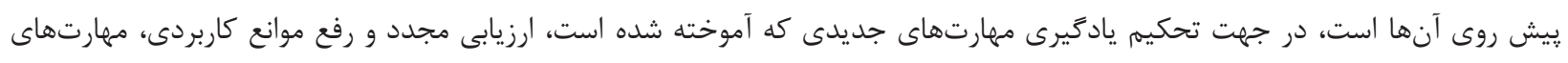


كدام از آزمودنىها از يزوهش حذف نشدند و rا ا نفر از آزمودنىها

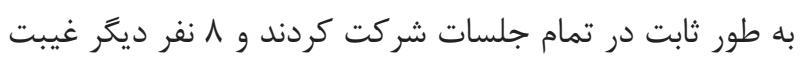

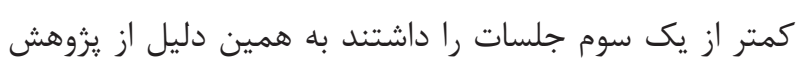

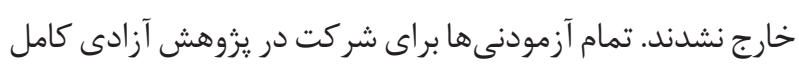
داشته و سعى شد جلسات درمانى در وقت آزاد آزمودنى ها بركزار

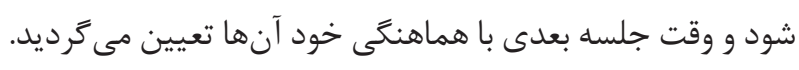

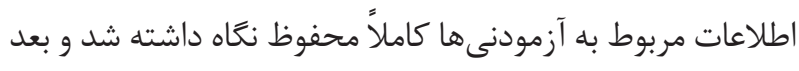

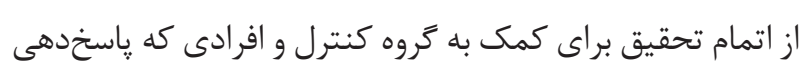

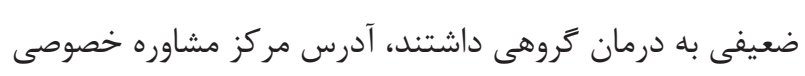

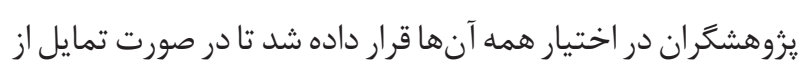

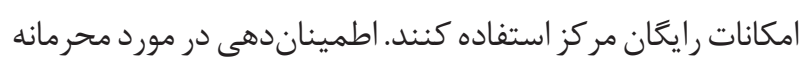

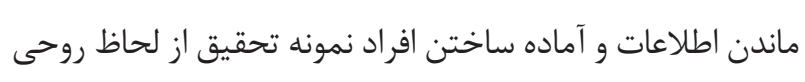

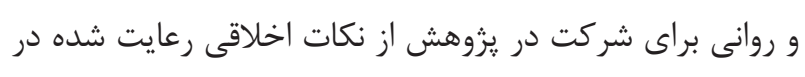
اين يزوهش بود. محتواى مداخله به شرح زير بود:

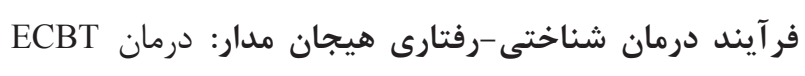
1. (Emotion-Focused Cognitive Behavioral Therapy) جلسه و هفتهاى يك جلسه به مدت •9 دقيقه برَزار شد (11).

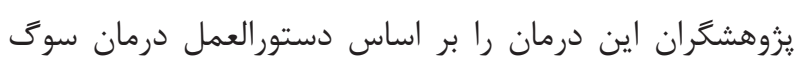
(Suveg)

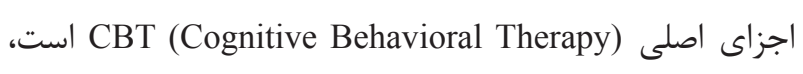

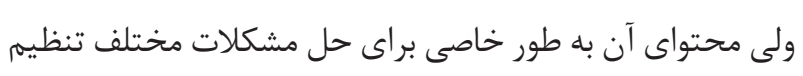

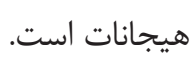

براى جمعآورى دادهها از ابزارهاى زير استفاده شد:

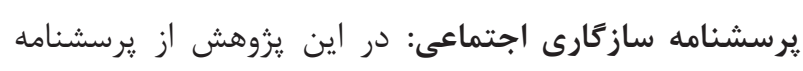
ساز كارى فردى -اجتماعى (SocialAdjustment Questionnaire) كه توسط بيكل و وايسمن (Paykel, Weissman) طراحى شده است، استفاده شد (سץ). اين مقياس شامل وظايف روزمره،

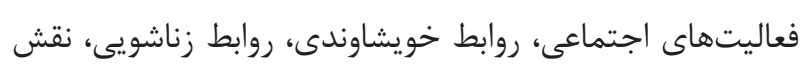

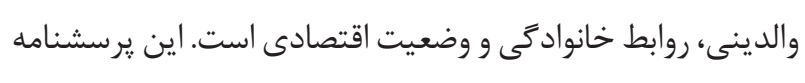

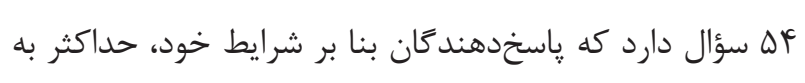

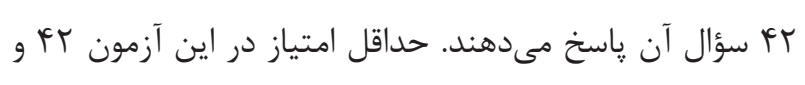

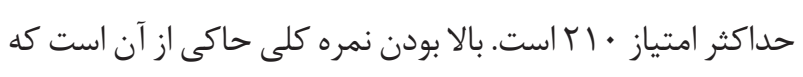

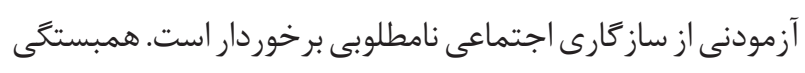

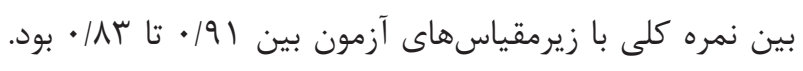

ماه و براى كروه دوم كه به عنوان كروه كنترل در نظر گرفته شد،

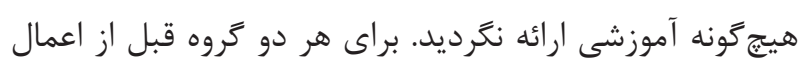

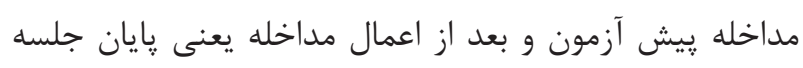

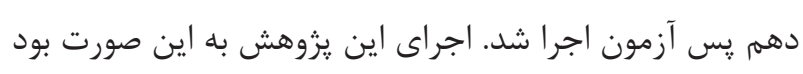

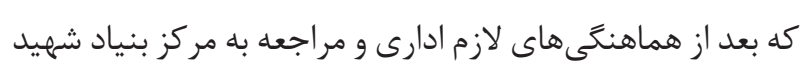
شهرستان كيلانغرب ليست تمامى افرادى كه به علت حوادث

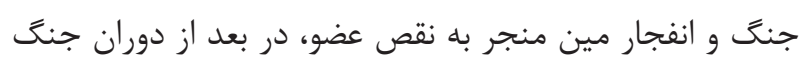

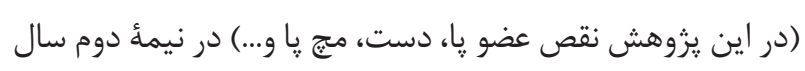

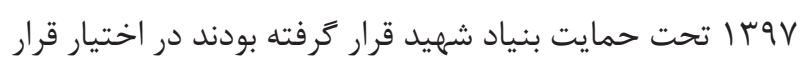

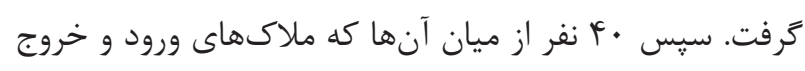

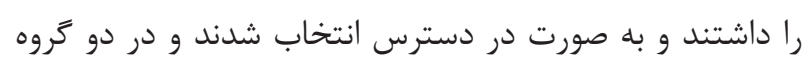

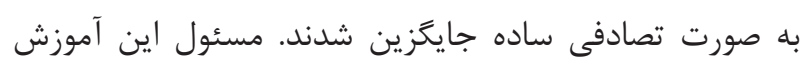

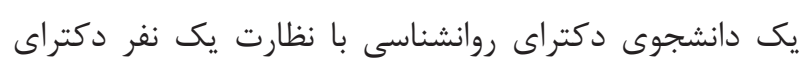

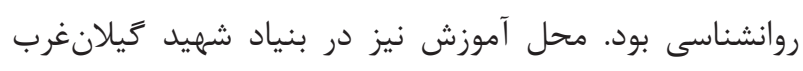

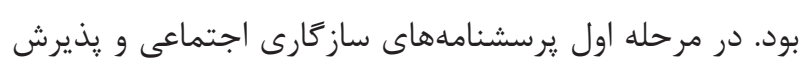

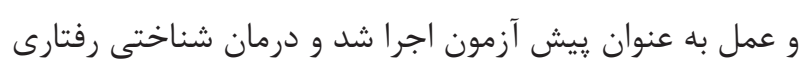

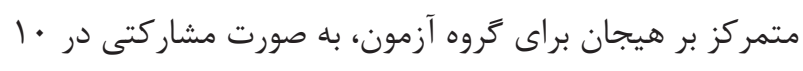

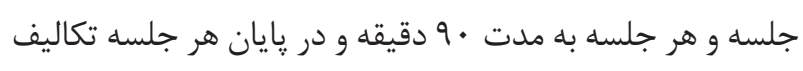

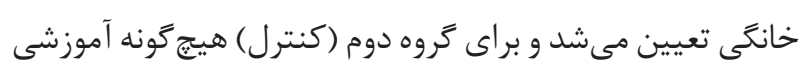

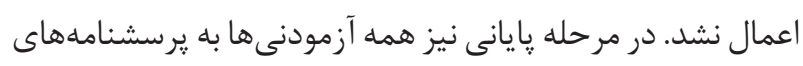

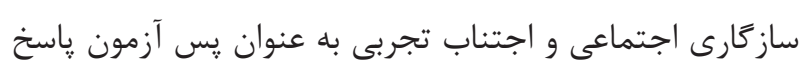

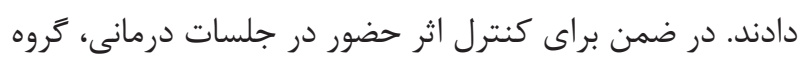

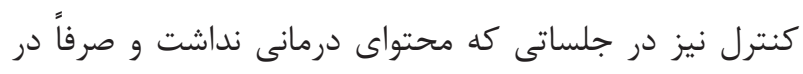

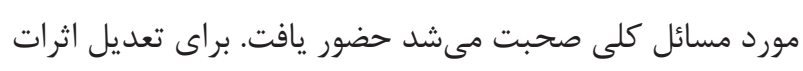

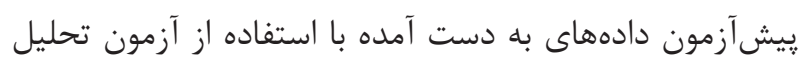

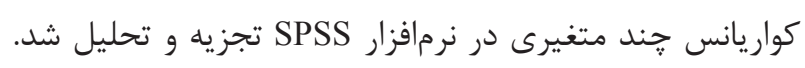
سطح معنادارى ه • • در نظر كرفته شد.

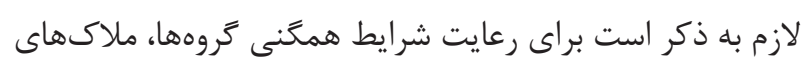

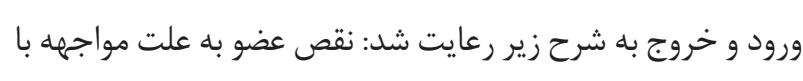

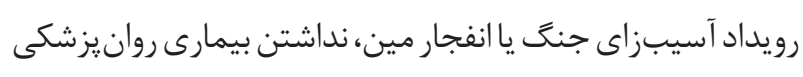

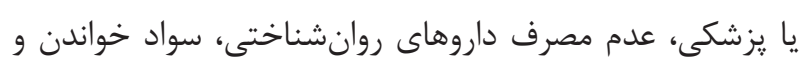

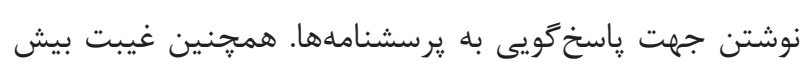

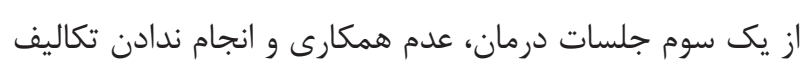

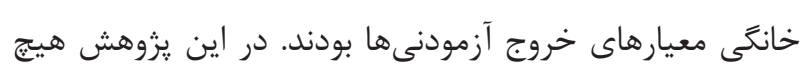


جدول r- ميانغين و انحراف معيار سازكًارى اجتماعى و اجتناب تجربى

\begin{tabular}{|c|c|c|}
\hline كروه كنترل & كروه آزمون & مرحله آزمون \\
\hline M \pm SD & $\mathrm{M} \pm \mathrm{SD}$ & \\
\hline$V Q / T r \pm \Lambda \Lambda / A T$ & VN/TYEQT/IV & سازگًارى اجتماعى \\
\hline$r \Psi / D \pm r M / K M$ & $r \Delta / \Delta \pm r / / 9 r$ & اجتناب تجربى \\
\hline$V V / T I \pm I T / \Lambda r$ & $Y \wedge / I \Delta \pm V V / \Delta r$ & سازكًارى اجتماعى \\
\hline r & $r q / r \pm 11 / r r$ & اجتناب تجربى \\
\hline
\end{tabular}

توجه به نمرهگذارى مقياس كه نمره پايين به معناى ساز كارى

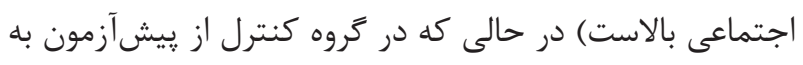

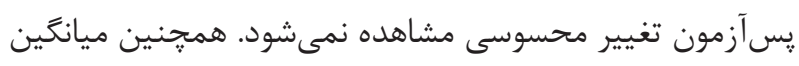

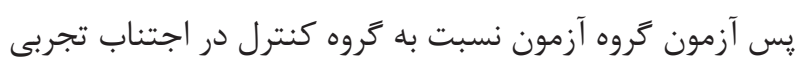
يايينتر است.

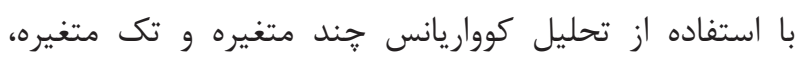
تفاوت بين دو گروه آزمون و كنترل از لحاظ تفاضل ميانگين

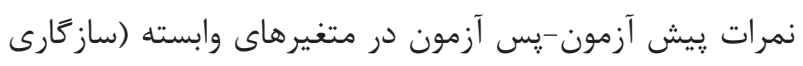

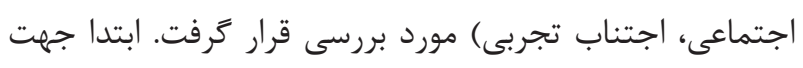

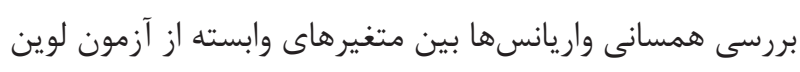

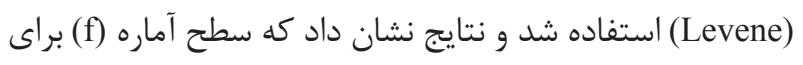

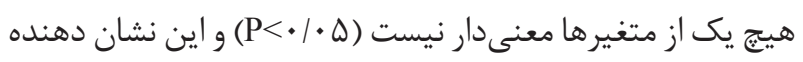

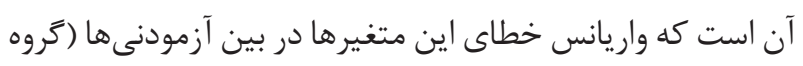

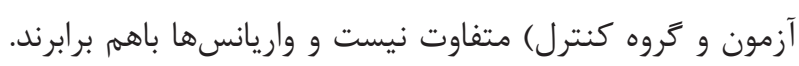

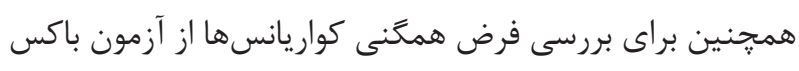
(Box)

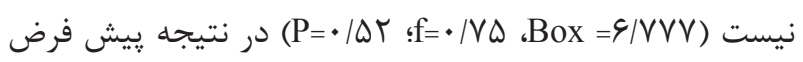

$$
\text { تفاوت بين كوواريانس ها برقرار است. }
$$

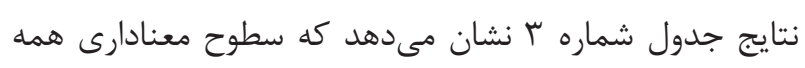

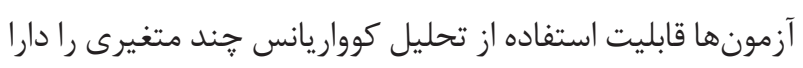
مىباشد. اين نتايج نشان مىدهد اين دو كروه آزمون و كنترل

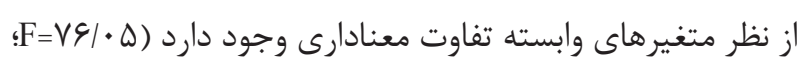

همان طورى كه در جدول شماره F مشاهده مىشود با كنترل

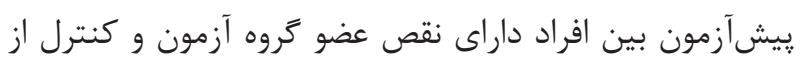

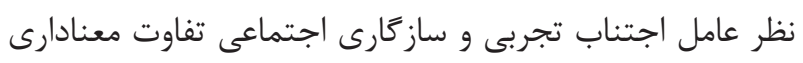

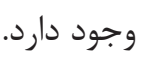

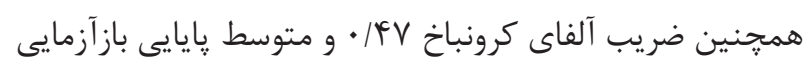

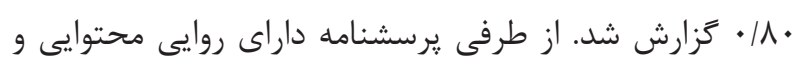

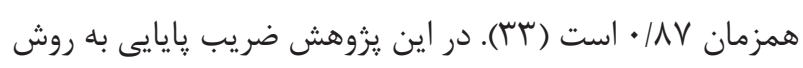

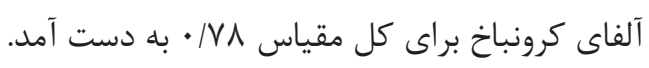

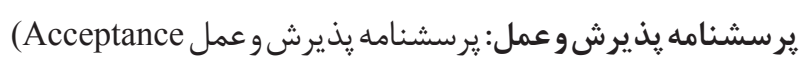
(MF) در بطن درمان يذيرش و تعهد (And Action Questionnaire) به عنوان ابزارى براى اندازهيرى اجتنابتجربى و انعطافنايذيرى

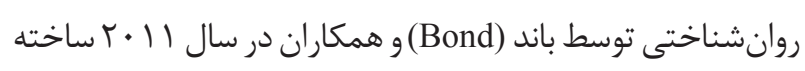

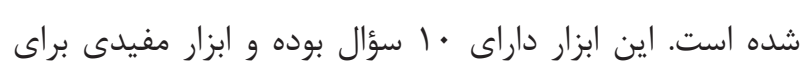

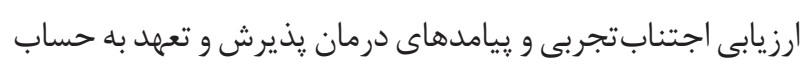

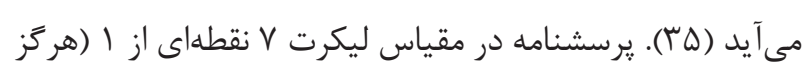

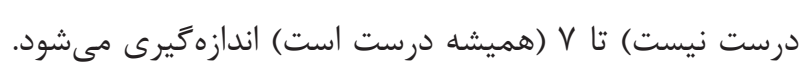

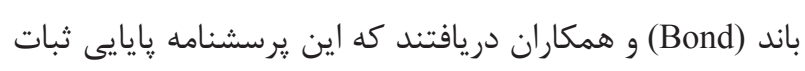

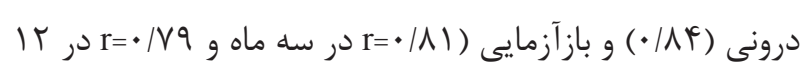

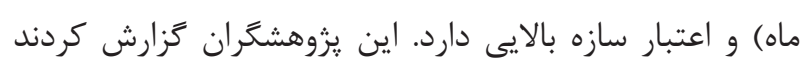

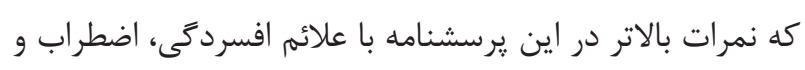

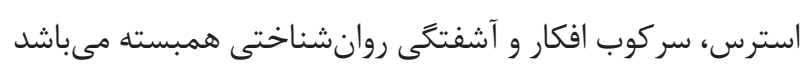

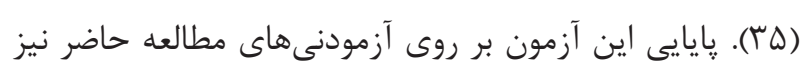

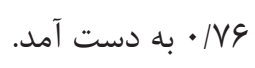

\section{يافتهها}

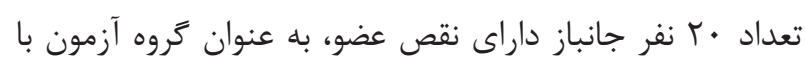

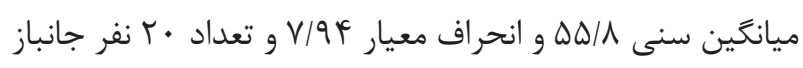

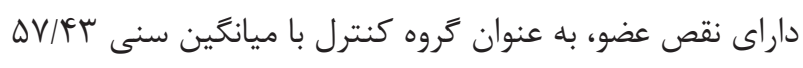

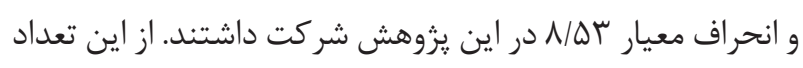

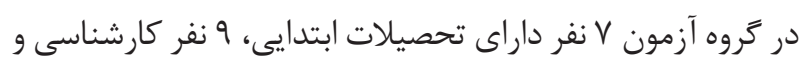

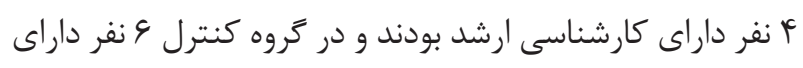
تحصيلات راهنمايى و 1 نفر دبيرستان، 9 نفر كارشناسى بودند كه در اين يزوهش شركت كردند.

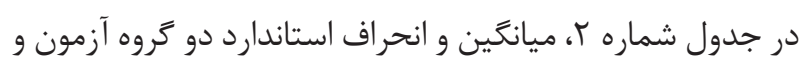

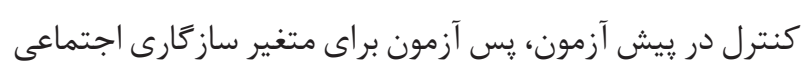

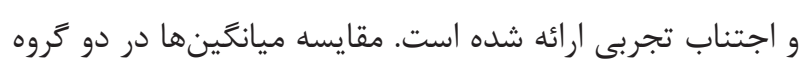

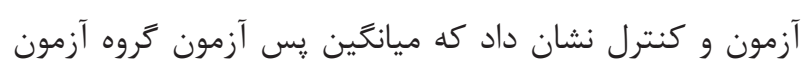

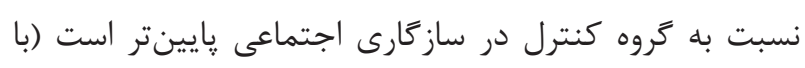


جدول ب- نتايج شاخصهاى اعتبارى آزمون معنادارى تحليل كوار يانس جند متغيرى بر متغير وابسته

\begin{tabular}{|c|c|c|c|c|c|c|}
\hline اندازه اثر & سطح معنادارى & خطاى درجه آزادى & فرضيه درجه آزادى & سطح آماره & نام آزمون & منبع \\
\hline .190 & $\cdot 1 \cdot \cdot 1$ & 11 & $\Delta$ & $V 9 / \cdot \Delta$ & اثرييلايى & \multirow{4}{*}{ حروه } \\
\hline .190 & $\cdot 1 \cdot \cdot 1$ & $\Delta$ & $\Delta$ & $V q / \cdot \Delta$ & لامبدا ويلكز & \\
\hline .190 & $.1 \cdot \cdot 1$ & $\Delta$ & $\Delta$ & $V q / \cdot \Delta$ & اثر هتلينگ & \\
\hline .190 & $.1 \cdot \cdot 1$ & $\Delta$ & $\Delta$ & $V \varepsilon / \cdot \Delta$ & بزرگترين ريشه خطا & \\
\hline
\end{tabular}

جدول F - نتايج آزمون تحليل كواريانس براى مقايسه تأثير روش درمان شناختى -رفتارى هيجان مدار بر سازكارى اجتماعى و اجتناب تجربى

\begin{tabular}{|c|c|c|c|c|c|}
\hline ميزان تأثير & معنادارى & سطح آماره & درجه آزادى & متغير وابسته & منبع تغييرات \\
\hline$\cdot|\pi|$ & $\cdot / \cdot \Delta \Lambda$ & $\Gamma / 10$ & 1 & اجتناب تجربى & \multirow{2}{*}{ يِش آزمون } \\
\hline$\cdot 1 \cdot 1$ & $\cdot / \Delta T$ & . & 1 & سازگًارى اجتماعى & \\
\hline$\cdot|9|$ & $\cdot 1 \cdot \cdot 1$ & TI/GT & r & اجتناب تجربى & \multirow{2}{*}{ يس آزمون } \\
\hline$\cdot|0|$ & $.1 \cdot 1 \mathrm{~V}$ & $q / 1 \vee \Delta$ & 1 & سازكًارى اجتماعى & \\
\hline
\end{tabular}

صورت منفى ارزيابى كنند و كمتر خود را در موقعيتهاى اجتماعى

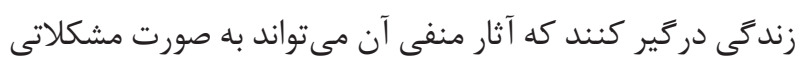
در ابعاد سازكارى اجتماعى، هيجانى ظاهر شود؛ اما اين درمان باعث مىشود كه از وجود هيجانهاى منفى و تأثير منفى آنها

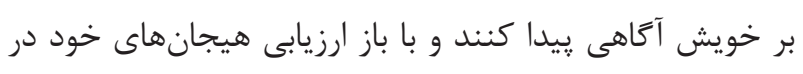

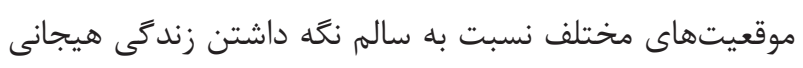

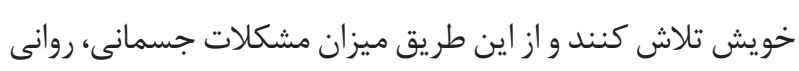

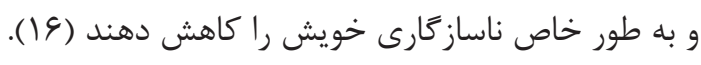

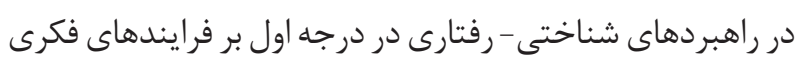

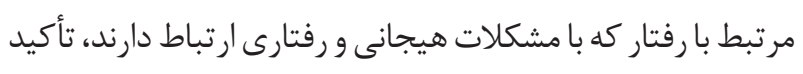
مىشود و با كمك به فرد براى تغيير افكار خود در مورد تجارب

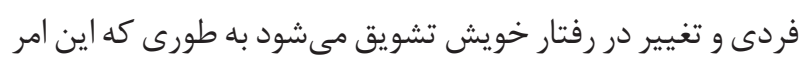

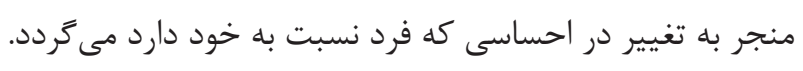

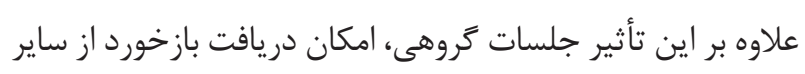
اعضاى كروه، ايجاد حس همدلى و مشاهده نوع مقابله ديخران

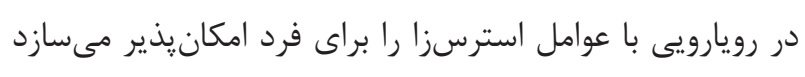

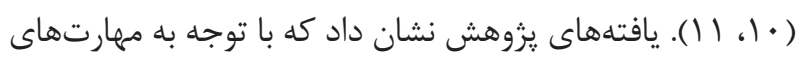

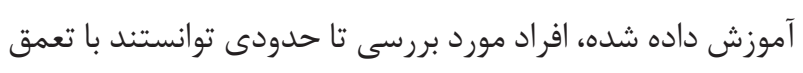

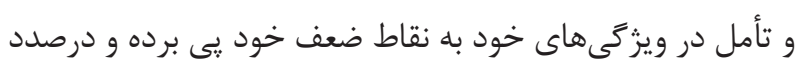

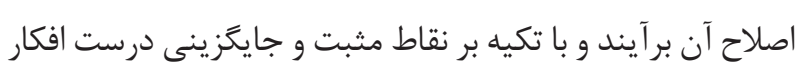
منطقى به جاى تحريفات شناختى نامطلوب؛ سعى در بهبودى
بحث و نتيجه تيرى

در يزوهش حاضر اثر بخشى روش درمان شناختى -رفتارى هيجان

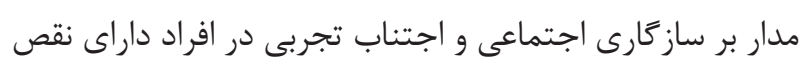

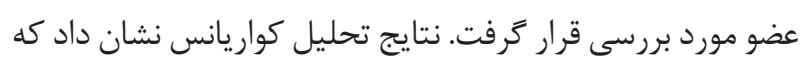

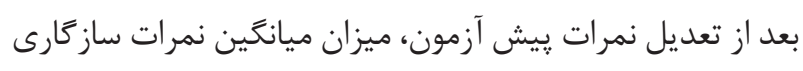

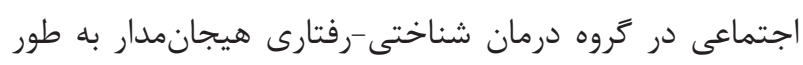

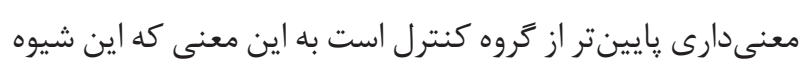

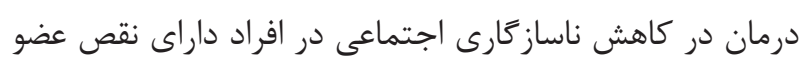

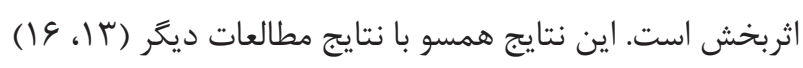

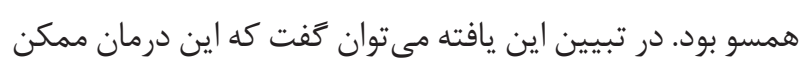

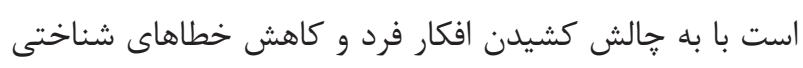

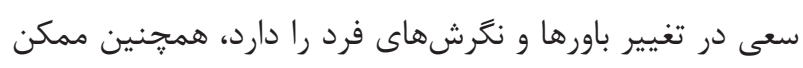

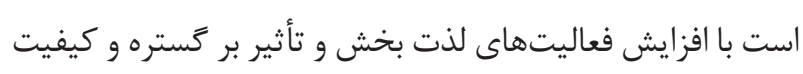

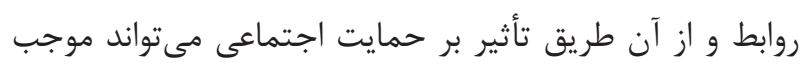

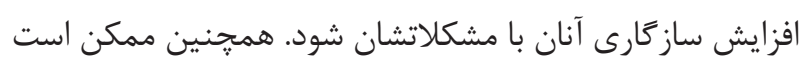

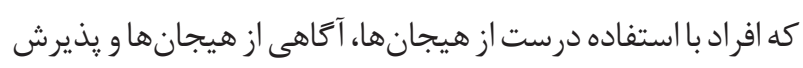

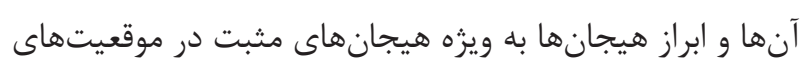

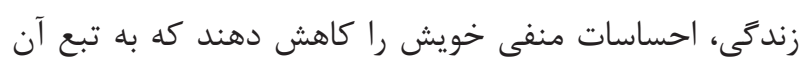

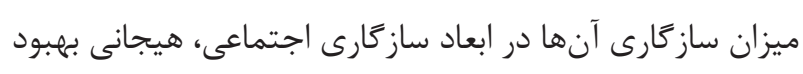

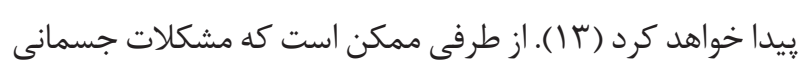
و روانى آنها باعث شود كه در موقعيتهاى اجتماعى، خود را به إنه 
سطوح بالاى هيجانات مثبت و كاهش هيجانات منفى نقش مهمى

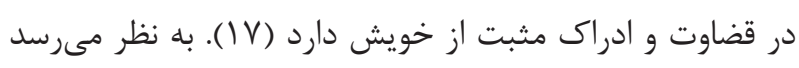

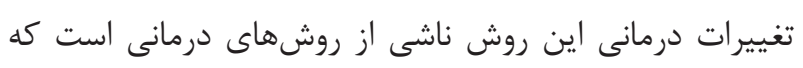

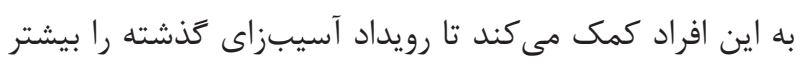

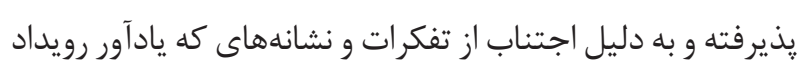
آسيبزايى كه منجر به نقص عضو شده، يرهيز نموده و به جاى دئه

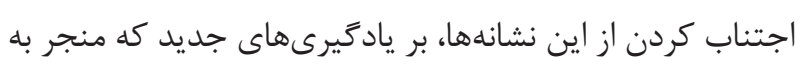

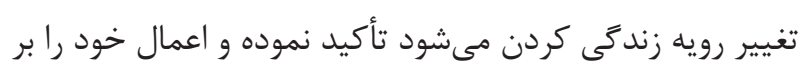
اساس حركت در مسير يادخيرىهاى جديد سازماندهى نمايند

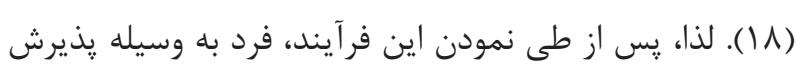
تفكرات مثبت و مواجهه شدن با صحنهها و مكان هاى كه از آنها

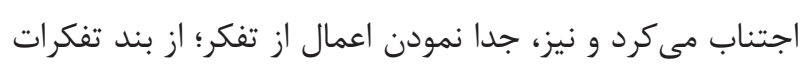

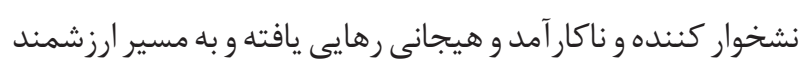

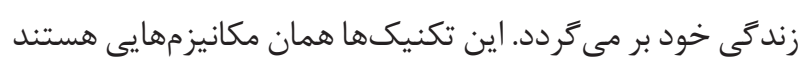

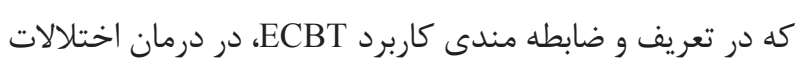

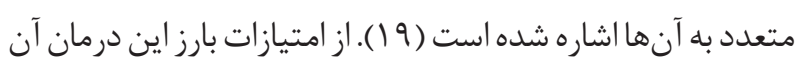

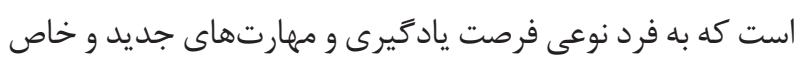

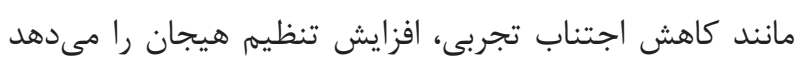

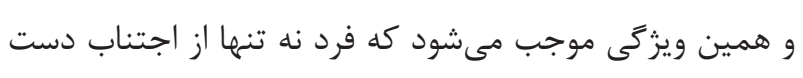

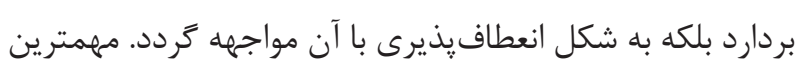

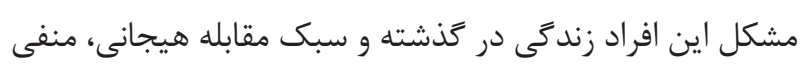

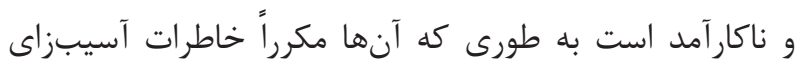

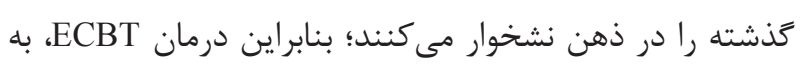

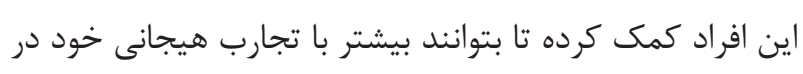

تماس باشند (·) (广). با بررسى نقش اجتناب در همبودى اختلالات روانى، مىتوان به به (بله

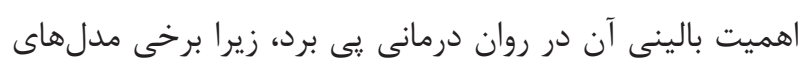
درمانى شناختى -رفتارى بر اهميت اجتناب تأكيد دارند (1) 1 ، 9 (1).

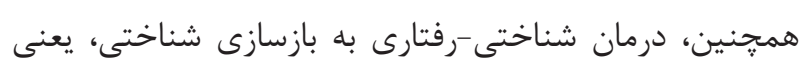

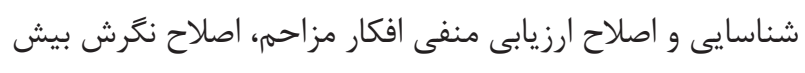

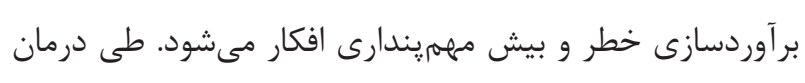

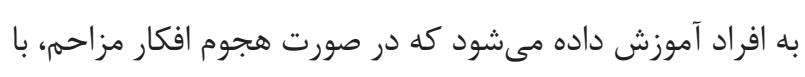
به كار كيرى روشهاى درمانى مناسب با آنها مقابله كنند (· (Y).

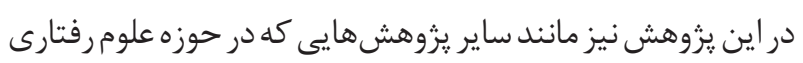

افكار، احساسات و عواطف خود با ديخران داشته باشند (T؟).

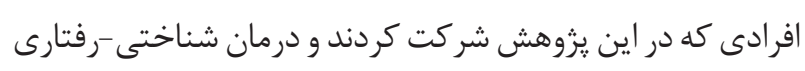
هيجان مدار را دريافت كردند، ممكن است ياد كرفته باشند كه دهن

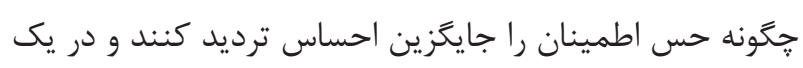

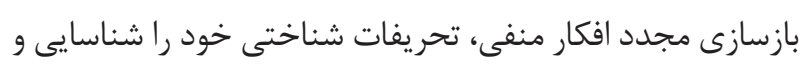

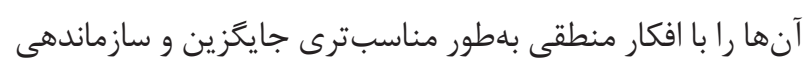

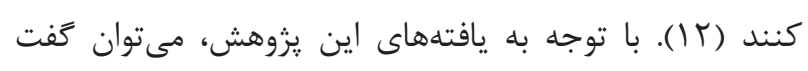

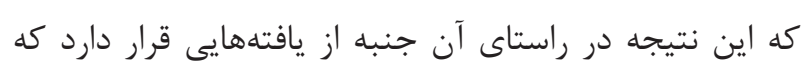

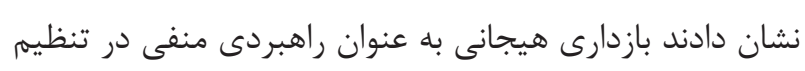

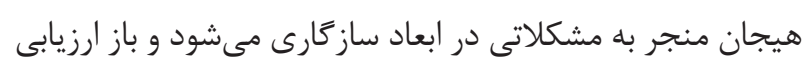

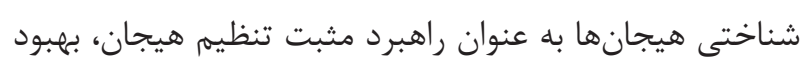

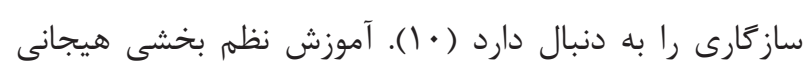

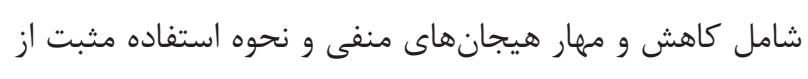

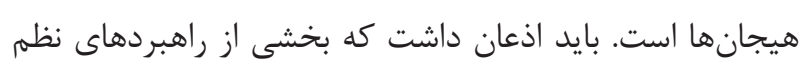

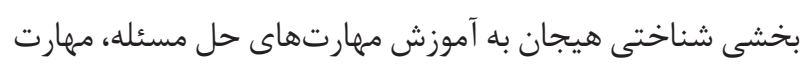

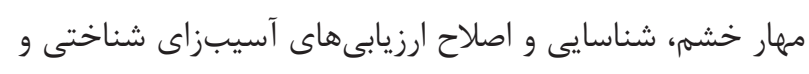

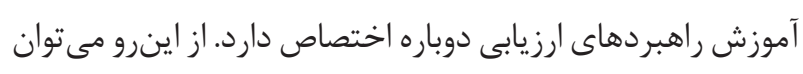

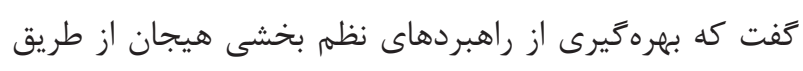

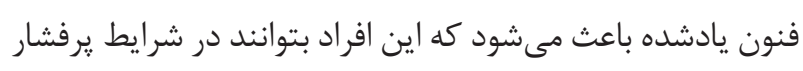

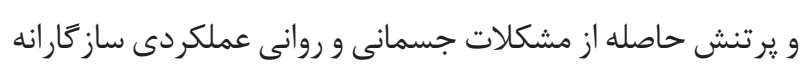

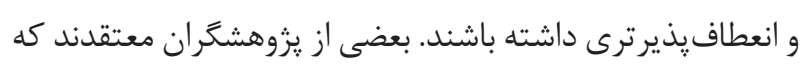

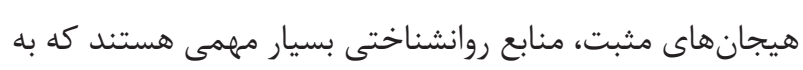

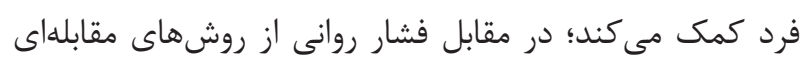
مؤثرى استفاده كند (11) - (1).

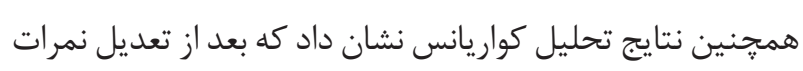

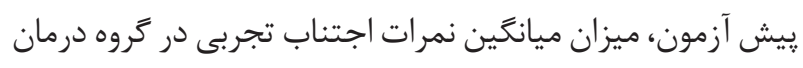

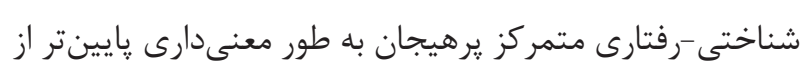

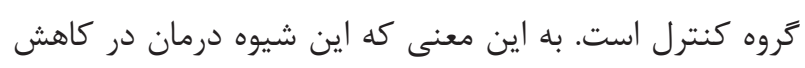
اجتناب تجربى در افراد داراى نقص عضوى اثر بخش است. اين اين

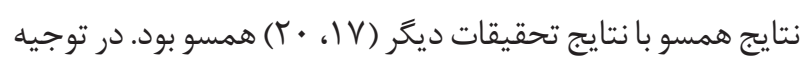

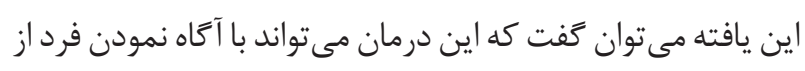

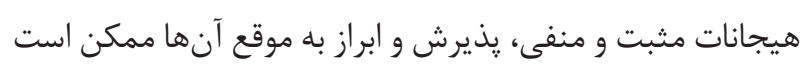

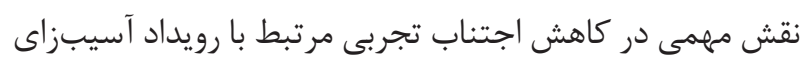

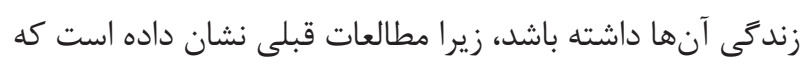


بيشتر و در مناطق ديخر كشور نيز صورت گيرد و در مطالعات مشابه آتى، براى ييشخيرى از سوخيرى احتمالى در تشخيص و ارزيابى، از روشهاى ديخرى مانند مصاحبه بالينى استفاده شود.

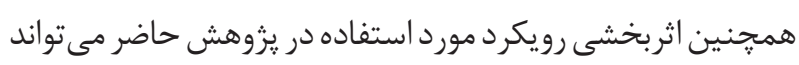
در نمونه هاى بالينى مبتلا به مشكلات روانشناختى مختلف مورد بررسى قرار گيرد و نيز ييشنهاد مى شود كه اين رويكرد درمانى مبنى با ديخر رويكردهاى درمانى در جامعه ايرانى مورد مقايسه قرار

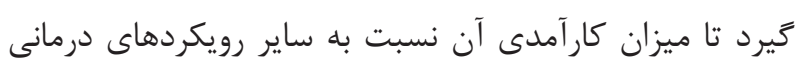
مشخص شود.

تشكر و قدردانى

از همكارى و همراهى صميمانه كاركنان بنياد شهيد شهرستان حيلان غرب و جانبازان مشاركت كننده در اين يروهش صميمانه سياسگزارى مىشود.

\section{تضاد منافع}

بدين وسيله نويسندكان تصريح مىنمايند كه هيجزَنه تضاد منافعى در خصوص :ثروهش حاضر وجود ندارد.

\section{References}

1- Samadifard HR, Narimani M. Life Expectancy in the Spouses of Veterans. Iranian Journal of War and Public Health. 2018;10(3):151-6. http://dx.doi.org/10.29252/ijwph.10.3.151

2- Cushing RE, Braun KL. Mind-Body Therapy for Military Veterans with Post-Traumatic Stress Disorder: A Systematic Review. J Altern Complement Med. 2018;24(2):106-14. http://dx.doi.org/10.1089/ acm.2017.0176 www.ncbi.nlm.nih.gov/pubmed/28880607

3- Armenta RF, Rush T, LeardMann CA, Millegan J, Cooper A, Hoge $\mathrm{CW}$, et al. Factors associated with persistent posttraumatic stress disorder among U.S. military service members and veterans. BMC Psychiatry. 2018;18(1):48. http://dx.doi.org/10.1186/s12888-0181590-5 www.ncbi.nlm.nih.gov/pubmed/29452590

4- Hasani Tabatabai L, Shaker Dioulagh A. Comparison of Stress and Social Support between Veterans and Non-Veterans; Case Study of Urmia City, Iran. Iranian J War \& Public Health. 2017;9(3):141-6. http://dx.doi.org/10.18869/acadpub.ijwph.9.3.141

5- Kopacz MS, Ames D, Koenig HG. Association Between Trust and Mental, Social, and Physical Health Outcomes in Veterans and Active Duty Service Members With Combat-Related PTSD Symptomatology. Front Psychiatry. 2018;9:408. http:// dx.doi.org/10.3389/fpsyt.2018.00408 www.ncbi.nlm.nih.gov/
و روانشناسى انجام شده محدوديتهايى وجود دارد، از جمله اثر اجراى ييشآزمون بر نمرات يس آزمون و عدم اجراى بيگيرى به منظور بررسى تداوم اثربخشى روشهاى مورد استفاده و انتخاب نمونه يزوهش به صورت در دسترس بود، از ديگر محدوديتهاى يزوهش حاضر، كنترل نكردن متغيرهايى مانند نوع و مقدار نقص عضو يا درصد جانبازى و ميزان حمايت اجتماعى دريافت شده است كه مىتواند بر نتايج تحقيق اثر بحذارد، بنابراين ريشنهاد مىشود مطالعات آتى با كنترل اين متغيرها انجام گيرد. همجنين اثربخشى رويكرد مورد استفاده در يزوهش حاضر مىتواند در نمونههاى بالينى مبتلا به مشكلات روانشناختى مختلف مورد بر برسى قرار زيرد. درمان شناختى -رفتارى هيجان مدار با تأكيد بر اصلاح شناختهاى تحريف شده و آموزش رفتارهاى جديد، درى آكاهى هيجان، فهلم هيجان و تنظيم هيجان بر افزايش سازگًارى اجتماعى و كاهش اجتناب تجربى مؤثر است. نظم بخشى هيجانى و به ويزه راهبرد مثبت بازارزيابى شناختى هيجانها باعث كاهش احساسات منفى و افزايش احساسات مثبت و رفتار سازكارانه افراد مىشود. به منظور تعميم بيشتر نتايج ييشنهاد مىشود اين يروهش با تعداد نمونه

pubmed/30233429

6- Waqas A, Raza N, Zahid T, Rehman A, Hamid T, Hanif A, et al. Predictors of post-traumatic stress disorder among burn patients in Pakistan: The role of reconstructive surgery in postburn psychosocial adjustment. Burns. 2018;44(3):620-5. http:// dx.doi.org/10.1016/j.burns.2017.09.012 www.ncbi.nlm.nih.gov/ pubmed/29287731

7- Kelly MM, DeBeer BB, Meyer EC, Kimbrel NA, Gulliver SB, Morissette SB. Experiential avoidance as a mediator of the association between posttraumatic stress disorder symptoms and social support: A longitudinal analysis. Psychol Trauma. 2019;11(3):353-9. http://dx.doi.org/10.1037/tra0000375 www. ncbi.nlm.nih.gov/pubmed/30525774

8- Serrano-Ibanez ER, Ramirez-Maestre C, Esteve R, LopezMartinez AE. The behavioural inhibition system, behavioural activation system and experiential avoidance as explanatory variables of comorbid chronic pain and posttraumatic stress symptoms. Eur J Psychotraumatol. 2019;10(1):1581013. http:// dx.doi.org/10.1080/20008198.2019.1581013 www.ncbi.nlm.nih. gov/pubmed/30891160

9- Strombom Y, Karlsson J, Fredrikson M, Melin L, Magnusson P. 
Cognitive behavioral therapy for frequent attenders in primary care. Health Sci Rep. 2018;1(9):e80. http://dx.doi.org/10.1002/ hsr2.80 www.ncbi.nlm.nih.gov/pubmed/30623103

10- Sugiura Y, Sugiura T. Emotional intensity reduces later generalized anxiety disorder symptoms when fear of anxiety and negative problem-solving appraisal are low. Behav Res Ther. 2015;71:2733. http://dx.doi.org/10.1016/j.brat.2015.05.015 www.ncbi.nlm. nih.gov/pubmed/26057437

11- Timulak L, Keogh D, Chigwedere C, Wilson C, Ward F, Hevey D, et al. A comparison of emotion-focused therapy and cognitivebehavioural therapy in the treatment of generalised anxiety disorder: study protocol for a randomised controlled trial. Trials. 2018;19(1):506. http://dx.doi.org/10.1186/s13063-018-2892-0 www.ncbi.nlm.nih.gov/pubmed/30231910

12- Nielsen SKK, Hageman I, Petersen A, Daniel SIF, Lau M, Winding $\mathrm{C}$, et al. Do emotion regulation, attentional control, and attachment style predict response to cognitive behavioral therapy for anxiety disorders? - an investigation in clinical settings. Psychother Res. 2019;29(8):999-1009. http://dx.doi.org/10.1080/10503307.2018.1 425933 www.ncbi.nlm.nih.gov/pubmed/29357764

13- Omar M, Elfaydi F, Mikail L, Rashed K. Post-traumatic Stress Disorder and Psychological and Social Adjustment among Libyan Who Participated in 17th of February Revolution: A Structural Equation Modeling Analysis. International Journal of Social Science and Humanity. 2016;6(9):677-80. http://dx.doi. org/10.18178/ijssh.2016.6.9.731

14- Sippel LM, Watkins LE, Pietrzak RH, Hoff R, Harpaz-Rotem I. The Unique Roles of Emotional Numbing and Arousal Symptoms in Relation to Social Connectedness Among Military Veterans in Residential Treatment for PTSD. Psychiatry. 2018;81(3):271-82. http://dx.doi.org/10.1080/00332747.2017.1395313 www.ncbi. nlm.nih.gov/pubmed/30015602

15- Hassija CM, Garvert DW, Cloitre M. Brief Report: Symptoms of PTSD, Coping Strategies, and Social Adjustment among Survivors of Early Life Interpersonal Trauma. J Aggression, Maltreatment \& Trauma. 2015;24(5):520-31. http://dx.doi.org/10.1080/10926771. 2015.1029178

16- Hori H, Kim Y. Inflammation and post-traumatic stress disorder. Psychiatry Clin Neurosci. 2019;73(4):143-53. http://dx.doi. org/10.1111/pcn.12820 www.ncbi.nlm.nih.gov/pubmed/30653780

17- Bardeen JR. Short-term pain for long-term gain: the role of experiential avoidance in the relation between anxiety sensitivity and emotional distress. J Anxiety Disord. 2015;30:113-9. http:/ dx.doi.org/10.1016/j.janxdis.2014.12.013 www.ncbi.nlm.nih.gov/ pubmed/25723652

18- Bardeen JR, Fergus TA. The interactive effect of cognitive fusion and experiential avoidance on anxiety, depression, stress and posttraumatic stress symptoms. J Contextual Behav Sci. 2016;5(1):1-6. http://dx.doi.org/10.1016/j.jcbs.2016.02.002

19- Williams JL, Hardt MM, Henschel AV, Eddinger JR. Experiential avoidance moderates the association between motivational sensitivity and prolonged grief but not posttraumatic stress symptoms. Psychiatry Res. 2019;273:336-42. http://dx.doi. org/10.1016/j.psychres.2019.01.020 www.ncbi.nlm.nih.gov/ pubmed/30682554

20- Goldstein B, Bradley B, Ressler KJ, Powers A. Associations Between Posttraumatic Stress Disorder, Emotion Dysregulation, and Alcohol Dependence Symptoms Among Inner City Females. J Clin Psychol. 2017;73(3):319-30. http://dx.doi.org/10.1002/ jclp.22332 www.ncbi.nlm.nih.gov/pubmed/27467499

21- Oster C, Morello A, Venning A, Redpath P, Lawn S. The health and wellbeing needs of veterans: a rapid review. BMC Psychiatry. 2017;17(1):414. http://dx.doi.org/10.1186/s12888-017-1547-0 www.ncbi.nlm.nih.gov/pubmed/29284431

22- Horesh D, Lowe SR, Galea S, Aiello AE, Uddin M, Koenen KC. An in-depth look into PTSD-depression comorbidity: A longitudinal study of chronically-exposed Detroit residents. J Affect Disord. 2017;208:653-61. http://dx.doi.org/10.1016/j.jad.2016.08.053 www.ncbi.nlm.nih.gov/pubmed/27816322

23- Tay AK, Rees S, Chan J, Kareth M, Silove D. Examining the broader psychosocial effects of mass conflict on PTSD symptoms and functional impairment amongst West Papuan refugees resettled in Papua New Guinea (PNG). Soc Sci Med. 2015;132:70-8. http:// dx.doi.org/10.1016/j.socscimed.2015.03.020 www.ncbi.nlm.nih. gov/pubmed/25795990

24- McDevitt-Murphy ME, Luciano MT, Tripp JC, Eddinger JE. Drinking motives and PTSD-related alcohol expectancies among combat veterans. Addict Behav. 2017;64:217-22. http://dx.doi. org/10.1016/j.addbeh.2016.08.029 www.ncbi.nlm.nih.gov/ pubmed/27664565

25- Bowen S, De Boer D, Bergman AL. The role of mindfulness as approach-based coping in the PTSD-substance abuse cycle. Addict Behav. 2017;64:212-6. http://dx.doi.org/10.1016/j. addbeh.2016.08.043 www.ncbi.nlm.nih.gov/pubmed/27664564

26- Simons JS, Simons RM, O’Brien C, Stoltenberg SF, Keith JA, Hudson JA. PTSD, alcohol dependence, and conduct problems: Distinct pathways via lability and disinhibition. Addict Behav. 2017;64:185-93. http://dx.doi.org/10.1016/j.addbeh.2016.08.044 www.ncbi.nlm.nih.gov/pubmed/27619010

27- Brown WJ, Wilkerson AK, Milanak ME, Tuerk PW, Uhde TW, Cortese BM, et al. An examination of sleep quality in veterans with a dual diagnosis of PTSD and severe mental illness. Psychiatry Res. 2017;247:15-20. http://dx.doi.org/10.1016/j. psychres.2016.07.062 www.ncbi.nlm.nih.gov/pubmed/27863313

28- Mikaeili N, Molavi P, Einy S, Tagavy R. Effectiveness of Emotion Focused Therapy on Emotional Dysregulation, Hopelessness and Suicidal Ideation in Post-Traumatic Stress Disorder Veterans. Iranian J War \& Public Health. 2017;9(3):111-7. http://dx.doi. org/10.18869/acadpub.ijwph.9.3.111

29- Teeters JB, Lancaster CL, Brown DG, Back SE. Substance use disorders in military veterans: prevalence and treatment challenges. Subst Abuse Rehabil. 2017;8:69-77. http://dx.doi.org/10.2147/ SAR.S116720 www.ncbi.nlm.nih.gov/pubmed/28919834

30- Raskind MA, Peskind ER, Chow B, Harris C, Davis-Karim A, 
Holmes HA, et al. Trial of Prazosin for Post-Traumatic Stress Disorder in Military Veterans. N Engl J Med. 2018;378(6):507-17. http://dx.doi.org/10.1056/NEJMoa1507598 www.ncbi.nlm.nih. gov/pubmed/29414272

31- Delavar A. Research Methods in Psychology and Educational Sciences. 6sd ed. Tehran: Viraesh Press; 1999.

32- Suveg C, Jones A, Davis M, Jacob ML, Morelen D, Thomassin K, et al. Emotion-Focused Cognitive-Behavioral Therapy for Youth with Anxiety Disorders: A Randomized Trial. J Abnorm Child Psychol. 2018;46(3):569-80. http://dx.doi.org/10.1007/s10802017-0319-0 www.ncbi.nlm.nih.gov/pubmed/28580504

33- Paykel ES, Weissman M, Prusoff BA, Tonks CM. Dimensions of social adjustment in depressed women. J Nerv Ment Dis.
1971;152(3):158-72. http://dx.doi.org/10.1097/00005053197103000-00002 www.ncbi.nlm.nih.gov/pubmed/5547811

34- Fernandez-Rodriguez C, Paz-Caballero D, Gonzalez-Fernandez S, Perez-Alvarez M. Activation vs. Experiential Avoidance as a Transdiagnostic Condition of Emotional Distress: An Empirical Study. Front Psychol. 2018;9:1618. http://dx.doi.org/10.3389/ fpsyg.2018.01618 www.ncbi.nlm.nih.gov/pubmed/30233461

35- Bond FW, Hayes SC, Baer RA, Carpenter KM, Guenole N, Orcutt HK, et al. Preliminary psychometric properties of the Acceptance and Action Questionnaire-II: a revised measure of psychological inflexibility and experiential avoidance. Behav Ther. 2011;42(4):676-88. http://dx.doi.org/10.1016/j.beth.2011.03.007 www.ncbi.nlm.nih.gov/pubmed/22035996 